\title{
Erratum to: Anti-tumor necrosis factor- $\alpha$ therapy and changes of flow-mediated vasodilatation in psoriatic and rheumatoid arthritis patients
}

Gianluigi Mazzoccoli • Incoronata Notarsanto - Gennaro Davide de Pinto • Mariangela Pia Dagostino - Angelo De Cata • Giuseppe D'Alessandro •

Roberto Tarquini - Gianluigi Vendemiale

Published online: 23 December 2010

(C) SIMI 2010

Erratum to: Intern Emerg Med (2010) 5:495-500

DOI 10.1007/s11739-010-0458-6

Unfortunately, the name of the fourth author was incorrectly given above the address on the title page of our article. The name is M. P. Dagostino as now given below.

The online version of the original article can be found under doi:10.1007/s11739-010-0458-6.

G. Mazzoccoli $(\bowtie) \cdot$ I. Notarsanto · G. D. de Pinto

M. P. Dagostino - A. De Cata

Department of Internal Medicine, Scientific Institute and

Regional General Hospital "Casa Sollievo della Sofferenza",

Opera di Padre Pio da Pietrelcina, Cappuccini Avenue,

71013 S. Giovanni Rotondo (FG), Italy

e-mail: g.mazzoccoli@tin.it

G. Vendemiale

Geriatrics Unit, Department of Medical Sciences,

University of Foggia, Foggia (FG), Italy

G. D'Alessandro

Department of Internal Medicine,

University of Foggia, Foggia, Italy

R. Tarquini

Department of Internal Medicine,

University of Florence, Florence, Italy 